\title{
Evaluating Online Learning Orientation Design With a Readiness Scale
}

\author{
Juhong Christie Liu \\ James Madison University
}

\begin{abstract}
Student online learning readiness (SOLR) has been identified as being closely associated with the success of learning in online environments. Online learning orientations have also been used as a key intervention to support students. However, the evaluation practice and research of online learning orientation design are limited. This research studied the effects of an orientation course on SOLR, using a multiyear design-based research with a one-group pretest and posttest method as the evaluation measurement. The design and implementation of a self-paced orientation course in Canvas learning management system was detailed as the intervention. A 20-item SOLR questionnaire was selected as the pretest and posttest instrument. After the initial cycles, a sample of 2,590 college students were invited to participate in the 2017 orientation and respond to the pretest and posttest. Because separate consent forms were distributed and collected at the pretest and posttest stages, the researcher was able to use 445 pretest and 624 posttest datasets. The independent samples $t$-test results indicated statistically significant improvement of SOLR competencies. The exploratory factor analysis results also indicated changes of items associated with the SOLR constructs. The reliability coefficients of all subscales were $>.90$, with an increase in the reliability of the SOLR instrument as a whole from pretest $(\alpha=.92)$ to posttest $(\alpha=.95)$. Implications for the design and evaluation of online learning orientations and preparing student online learning readiness are discussed toward future design and implementation.
\end{abstract}

Keywords: student online learning readiness, orientation for online learning, design research, structure and interaction, evaluation

Liu, J.C. (2019). Evaluating online learning orientation design with a readiness scale. Online Learning, 23(4), 42-61. doi:10.24059/olj.v23i4.2078

\section{Evaluating Online Learning Orientation Design With a Readiness Scale}

Supporting student success in learning has been the core value of education, regardless of formats (Entwistle \& Ramsden, 2015; Johnson, Stewart, \& Bachman, 2015). The ubiquity of online access to information and communication, flexibility of time and space of learning, and development of online pedagogy have led to the fact that online learning is becoming an integral part of curriculum and instruction. According to the 2018 Online Learning Consortium (OLC) and Babson Research Group, after a decade of stable increase in online enrollment, in fall 2016 more than $30 \%$ of students in higher education took at least one course in an online environment (Seaman, Allen, \& Seaman, 2018). 
Online learning provides opportunities and challenges for students (Kauffman, 2015). Because of the self-regulated nature of online learning and distance between instructors and students, supporting student success in online learning environments has demonstrated dimensions that are different from meeting the needs of on-campus students (Broadbent \& Poon, 2015; Cho \& Heron, 2015; Kauffman, 2015; Moore \& Kearsley, 2011). Dependency on technologies and media for accessing instructional content and instructors; distance between students and enrolled institutions as well as their class community members, including instructors and classmates; and adjustment to online discourse and interaction (Kaymak \& Horzum, 2013; Moore \& Kearsley, 2011) may present daunting barriers to online students. Finding how to prepare students to successfully fulfill learning performance in online environments has become one of the core research interests in online course design and program administration (Chan, 2017; Lieberman, 2017; Online Learning Consortium, 2016).

Research studies have found that students' online learning readiness (SOLR) affects their academic achievement (Mosa, Mahrin, \& Ibrrahim, 2016; Yilmaz, 2017). Online learning readiness is defined as "cognitive awareness and maturity that a student develops for successful learning in a Web-based environment. It manifests in the attributes of recognizing the self-directed nature, formulating learning strategies, obtaining technology competencies, adjusting to digital etiquettes, and being open for help-seeking" (Liu \& Roberts-Kaye, 2016, p. 242). Intentional efforts have been invested in identifying these attributes and providing support to develop competencies that are fundamental to online learning success (Horzum, Kaymak, \& Gungoren, 2015; Yukselturk \& Bulut, 2007). In the meantime, orientation courses or programs are designed and offered to scaffold students' ability to obtain these competencies (Cigdem \& Ozturk, 2016; Liu \& Adams, 2017). These invite research and evaluation so that informed decisions can be made toward the design and implementation at course and curriculum levels (Farid, 2014; Hung, Chou, Chen, \& Own, 2010; Yu \& Richardson, 2015). Educational design research depends on evaluative feedback to inform and improve design of these programs (McKenney \& Reeves, 2019). For these reasons, the current study aims to answer the following research questions:

RQ1: How has student online learning readiness (SOLR) changed after taking a selfpaced asynchronous orientation course for online learning?

RQ2: How can SOLR be used to inform the design of online learning orientations?

\section{Review of Literature}

Readiness for online learning means the preparedness of students to perform learning activities in an online environment. It indicates multiple dimensions, including but not limited to comfort in learning with computers, self-regulated learning strategies, and perception of learning community. Most instruments that measure online learning readiness focus on technology preparation and independent study strategies for students (Broadbent \& Poon, 2015; Cho \& Heron, 2015; Dray, Lowenthal, Miszkiewicz, Ruiz-Primo, \& Marczynski, 2011; Hung, Chou, Chen, \& Own, 2010; Smith, Murphy, \& Mahoney, 2003). Recently, learning readiness in online environments evolves along the development of strategies in pedagogy, instructional design, active learning, and technology affordances for communication and collaboration, which embody more social-cultural activities (Cheon, Lee, Crooks, \& Song, 2012; Dabbagh, 2007). In a social-cultural activity system, learning activities in online learning environment have social and communication dimensions with the mediation of technologies. Learning can be optimized through discourse and 
interaction with communities primarily composed of instructor and peer learners, and in an online learning environment where support can come from personnel in the enrolled institution, libraries, academic program administration, student services, and possibly technical support from outside higher education institution (Baek, Evans, \& Barab, 2013; Broadbent \& Poon, 2015; Coleman \& Coleman, 2013). Therefore, the dimensions of social interaction and communication are also important for the design and evaluation of online learning orientation programs.

\section{Online Learning Readiness}

Online learning readiness has been found related to student motivation and academic achievement. Horzum, Kaymak, and Gungoren (2015) studied a convenience sample of 750 students in online learning from Sakarya University. With 420 participation datasets and a structural equation modeling analysis, the authors concluded that SOLR could predict motivation and perception of academic achievement. Cigdem and Ozturk (2016) studied 155 postsecondary military students in an online computer literacy course in a Turkish school. Using Hung, Chou, Chen, and Own's (2010) Online Learning Readiness Scale, the researchers studied the relationship between three constructs in the scale and student academic achievement, which was measured with the end-of-course grades. The three constructs included motivation for online learning, computer/Internet self-efficacy, and self-directed learning. The researchers concluded that selfdirection in online learning could strongly predict student achievement.

Yilmaz (2017) studied 236 undergraduate students in a flipped class. The content learning of the class took place mostly in online environments. Student e-learning readiness was measured, as well as their satisfaction and motivation, which was measured with Pintrich, Garcia, McKeachie, and Smith's (1991) Motivated Strategies for Learning Questionnaire (MSLQ). The E-learning Readiness Scale by Yurdugül and Demir (Yilmaz, 2017) included constructs of computer selfefficacy, Internet self-efficacy, online communication self-efficacy, self-directed learning, learner control, and motivation towards e-learning. A structural equation modeling was conducted as the data analysis. E-learning readiness was found to positively affect student satisfaction and MSLQ scores.

The research in learning science also discovered the importance of social dimensions in student readiness to success (Entwistle \& Ramsden, 2015; Horzum, Kaymak, \& Gungoren, 2015; Tinto, 1975). Yu and Richardson (2015) developed a SOLR model based on Tinto's (1975) student integration model (SIM), which was grounded in social system. The SOLR model consisted of four constructs: social competencies with instructor, communication competencies, social competencies with classmates, and technical competencies. The four-construct SOLR instrument was recently validated by $\mathrm{Yu}$ and Richardson (2015) and $\mathrm{Yu}$ (2018); see Table 1. $\mathrm{Yu}$ and Richardson (2015) tested the validity and reliability of the model with 331 students who took fully online courses through Blackboard Learn in the spring of 2014 in multiple majors of psychology, industrial engineering, animal science, computer science, political science, management, and communications. The exploratory factor analysis results statistically validated the four-factor structure of the SOLR as an instrument. The reliability test resulted in all Cronbach alphas $>.823$. 
Table 1

SOLR Questionnaire (Yu \& Richardson, 2015; Yu, 2018)

\begin{tabular}{|c|c|c|}
\hline Construct & Coding for analysis & Items \\
\hline \multirow[t]{6}{*}{$\begin{array}{l}\text { Technical } \\
\text { competencies }\end{array}$} & TechComp1 & $\begin{array}{l}\text { I have a sense of self-confidence in using computer } \\
\text { technologies for specific tasks. }\end{array}$ \\
\hline & TechComp2 & $\begin{array}{l}\text { I am proficient in using a wide variety of computer } \\
\text { technologies. }\end{array}$ \\
\hline & TechComp3 & I feel comfortable using computers. \\
\hline & TechComp4 & $\begin{array}{l}\text { I can explain the benefits of using computer } \\
\text { technologies in learning. }\end{array}$ \\
\hline & TechComp5 & $\begin{array}{l}\text { I am competent at integrating computer technologies } \\
\text { into my learning activities. }\end{array}$ \\
\hline & TechComp6 & $\begin{array}{l}\text { I am motivated to get more involved in learning } \\
\text { activities when using computer technologies. }\end{array}$ \\
\hline \multirow{5}{*}{$\begin{array}{l}\text { Social } \\
\text { competencies } \\
\text { with instructor }\end{array}$} & SocialComp-Instructor1 & Clearly ask my instructor questions. \\
\hline & SocialComp-Instructor2 & Initiate discussions with the instructor. \\
\hline & SocialComp-Instructor3 & Seek help from instructor when needed. \\
\hline & SocialComp-Instructor4 & $\begin{array}{l}\text { Timely inform the instructor when unexpected } \\
\text { situations arise. }\end{array}$ \\
\hline & SocialComp-Instructor5 & Express my opinions to instructor respectfully. \\
\hline \multirow{5}{*}{$\begin{array}{l}\text { Social } \\
\text { competencies } \\
\text { with classmates }\end{array}$} & SocialCompPeers1 & Develop friendship with my classmates. \\
\hline & SocialCompPeers2 & Pay attention to other students' social actions. \\
\hline & SocialCompPeers3 & $\begin{array}{l}\text { Apply different social interaction skills depending on } \\
\text { situations. }\end{array}$ \\
\hline & SocialCompPeers4 & Initiate social interaction with classmates. \\
\hline & SocialCompPeers5 & Socially interact with other students with respect. \\
\hline \multirow[t]{4}{*}{$\begin{array}{l}\text { Communication } \\
\text { competencies }\end{array}$} & CommComp1 & $\begin{array}{l}\text { I am comfortable expressing my opinion in writing to } \\
\text { others. }\end{array}$ \\
\hline & CommComp2 & I am comfortable responding to other people's ideas. \\
\hline & CommComp3 & $\begin{array}{l}\text { I am able to express my opinion in writing so that } \\
\text { others understand what I mean. }\end{array}$ \\
\hline & CommComp4 & $\begin{array}{l}\text { I give constructive and proactive feedback to others } \\
\text { even when I disagree. }\end{array}$ \\
\hline
\end{tabular}

Note. The instrument is cited with permission from the original author of the SOLR instrument.

Although the authors pointed out the limitations and future directions of this study, the significance of research was in its social aspects of identifying students' sense of social belonging in online learning environments. There were four constructs and 20 items in the SOLR instrument. Among them, the five items of social competencies with instructor and the five items with classmates had relevance to social presence and interaction in online learning environments (Kim, Kwon, \& Cho, 2011; Lee, 2014; Moore \& Kearsley, 2011). The five technical competencies and four communication competencies were commonly studied in online learning readiness researches (Dray, Lowenthal, Miszkiewicz, Ruiz-Primo, \& Marczynski, 2011; Hung, Chou, Chen, \& Own, 2010; Smith, Murphy, \& Mahoney, 2003). While some attributes of the Yu and Richardson SOLR can be expressions of student characteristics, research in online learning has indicated that proper scaffolding with supportive courses or programs can build student preparedness and strengthened readiness for online learning (Cigdem \& Ozturk, 2016; Glazer \& Murphy, 2015; Horzum, Kaymak, \& Gungoren, 2015; Kauffman, 2015; Liu \& Adams, 2017; Taylor, Dunn, \& Winn, 2015). 


\section{Online Learning Orientation}

As part of student services, educational organizations offering online programs or curricula have been providing various orientation programs or resources to support student success (Chan, 2017; Gray, 2004; Lieberman, 2017; Liu \& Adams, 2017; Liu \& Roberts-Kaye, 2016). These have been primarily focusing on technical training or support for students to be able to use media and technology to learn content and communicate with instructors and educational institutions from distant locations. Tools or technologies that are customized to a university or college, such as those relevant to the learning management system (LMS), help desk, and registration system, usually consist of the initial package of orientation materials (Scagnoli, 2001; Tomei, Hagel, Rineer, Mastandrea, \& Scolon, 2009). Through the evolving versions of online learning delivery technologies, these orientation materials have also been designed and packaged to meet the challenges of version compatibility (Scagnoli, 2001). Orientation courses could take an appealing appearance with interactive media (Taylor, Dunn, \& Winn, 2015). Some also included hands-on activities with which students could learn the essential LMS functions by completing meaningful activities, such as developing a discussion post, self-introduction wiki page, or completing a timemanagement worksheet and submitting it as an assignment (Carruth et al., 2010; Liu \& Adams, 2017).

Technical preparation was just the initial awareness and baseline of preparing student success, though. In 2008, after surveying the member and provider institutions of the Online Consortium of Independent College and Universities (OCICU) as well as online students, the researchers recommended including course syllabi in orientation packages and having orientation packages regularly reviewed to ensure quality and ease of use (Tomei et al., 2009). Williams and Hellman (2004) surveyed 829 college students in online learning environments about their selfregulated learning. The researchers used Bandura's Self-Efficacy Scale (1989) as the measure. With 708 complete data sets, the researchers conducted an ANCOVA analysis, which allowed the comparison of self-regulated learning between first-generation and second-generation college students. The findings disclosed that the first-generation students lacked self-regulated learning attributes and were less socially integrated and, therefore, more in need of scaffolding to gain the self-regulation skills and social competency for online learning success.

Orientation courses and programs have also started to become tuned in with the instructional and social dimensions of online curriculum. Gilmore and Lyons (2012) reported the effect of a nursing 911 orientation program. Students met for 8 hours at face-to-face meetings for the orientation, familiarizing themselves with the program, personnel, course structures, library resources, and social interaction patterns in online environments. With179 RN-to-BSN students, the dropout rate decreased from $20 \%$ to $1 \%$.

Carruth, Broussard, Waldmeier, Gauthier, and Mixon (2010) designed and implemented a one-week orientation online course for nursing students. The orientation provided an overview of the nursing program, expectations of students, principles of e-learning, and activities for students to build computer skills and the ability to use the LMS. After a pilot with 68 new students, the student feedback toward the orientation was very positive, with $97.5 \%$ commenting that they were able to perform skills needed for online learning and LMS navigation, and $95.2 \%$ indicating that they were able to critically reflect on technology's supportive role in their learning. The one-week orientation program in this study had the online presence of the three program coordinators throughout the course. The students were also provided practice activities that were closely related to their use of the LMS and setting career goals. 
Online learning orientation sessions can be a tool to improve retention for online learning (Beckford, 2015; Cho, 2012; Robichaud, 2016; Tomei et al., 2009). This type of tool can help students build understanding of the differences between online learning and the traditional learning experience (Beckford, 2015). Building upon technology literacy and access, these orientations can emphasize self-directed and self-disciplined learning. Time-management skills and capability need to be developed or strengthened through these orientations. To alleviate the sense of isolation in online learning environments, these orientations also need to prioritize the development of online communication skills so as to ensure meaning and intention are transmitted smoothly and accurately among members in a class or program. As essential components in online learning orientations, these attributes have been found as the characteristics associated with online learning success (Williams \& Hellman, 2004; Yukselturk \& Bulut, 2007).

Self-directed learning and online learning strategies were integral components in online learning orientations. Liu and Adams (2017) designed a self-reflective discussion about a successful online learner profile after students watched and read about online learning strategies. Students were also prompted to perform a hands-on exercise in which they were able to download a time-management template, read a short article about effective management of time, log one week of time distribution of study versus other activities with the template, and submit it as an assignment.

Chan (2017) studied online learning orientation programs offered by 100 randomly selected community colleges in 38 states. Among the 39 colleges that offered online-only (21) or in-person and online (18) orientations, topics related to online learning success remained just in technology competencies and access. Research in online learning indicated that supportive orientation programs need to take into consideration social, technical, and communication dimensions because of the constant interactions between humans and technologies in online learning environments (Kaptelinin \& Nardi, 2006; Scanlon \& Issroff, 2005; Uden, 2006).

\section{Design and Evaluation of Online Learning Orientation}

In essence, online learning orientations are designed to eliminate transactional distance, which is a default barrier in online learning because members in a learning community are not in the same physical location (Moore \& Kearsley, 2011). Reducing transactional distance can be realized with the design considerations of student-content, student-instructor, student-student, and student-context interactions (Moore \& Kearsley, 2011; Benson \& Samarawickrema, 2009). These dynamics to optimize interaction with structure should be applied to the design of online learning orientation courses or programs.

Studies found that when the structure of an online learning environment increased, interaction would decrease (Kaymak \& Horzum, 2013). Research also indicated that interactions were critical to student perceived satisfaction and social presence in online learning (Swan, 2001, 2002). Swan (2002) studied the role of interaction through analyzing the design factors of 73 courses and conducting content analysis of the online peer-to-peer discussion of one course. The researcher concluded that student-student interaction in online learning was important and that active and supportive verbal indicators were correlated with the sense of learning community and social presence.

So and Brush (2008) studied the design components of collaborative learning and peer interaction in correlation with student perceived satisfaction and social presence. The study was conducted in a health education graduate class. Fifty-five graduate students participated in the 
study. Collaboratively, the students developed an HIV-AIDS prevention community plan. The mixed methods study analyzed the quantitative data collected with Collaborative Learning, Social Presence, and Satisfaction (CLSS) questionnaire with exploratory factor analysis. The subsequent qualitative data collection was completed through interviews with students. The research findings revealed that communication media permitting immediate feedback and peer interaction were instrumental to collaborative learning and student perceived social presence.

These design propositions can be attuned with online learning orientation design. Furthermore, the effectiveness of the design is in need of more formalized evaluation, which "drives intervention development while at the same time seeking to inform an external scientific community of the results and their possible utility results" (McKenney \& Reeves, 2019, p. 161). Watts (2019) evaluated the effectiveness of an online student orientation (OSO) seminar embedded in a master's degree graduate program, using a Community of Inquiry (CoI) framework. A precourse survey, OSO assessment survey developed by the researcher, and a final reflection paper were used as data sources for evaluation. Fourteen graduate students participated in the OSO intervention and the evaluation. Precourse survey responses to open-ended questions indicated that students' perceived readiness in terms of time management, academic skills, communication, ability to use the LMS, and attitudinal actors, such as patience, were important to their success. As OSO activities, the students watched a short video about online learning strategies, participated in an online discussion, and wrote an essay based on the reading of a CoI paper. The evaluation results revealed that students felt OSO activities were useful, helping them build social presence through online discussion and synchronous learning, building confidence through peer interaction, and connecting cognitive and academic presence with their career-related work.

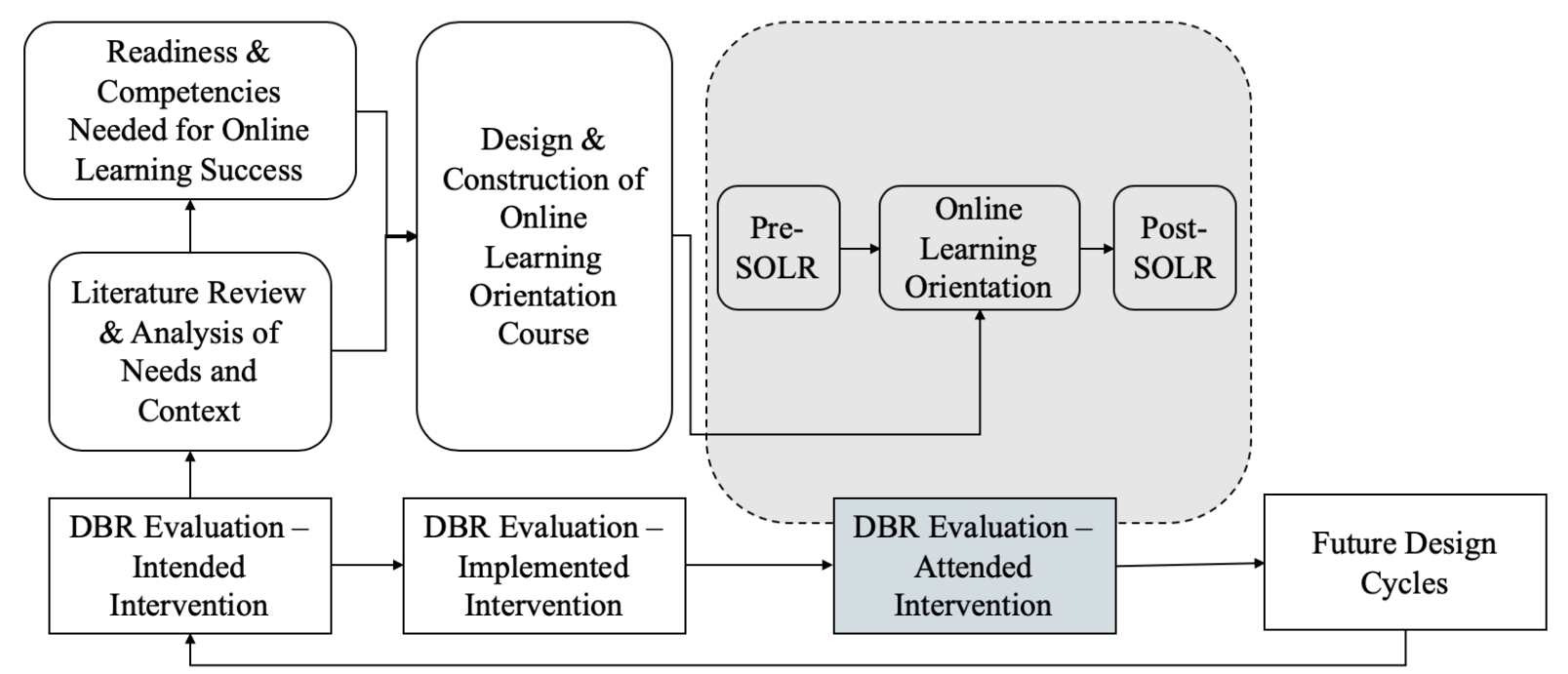

Figure 1. Conceptual framework of evaluation stages of this design research. 


\section{Research Design}

\section{Methods}

This study used a design-based research (DBR) approach and a one group pretest-posttest method as its evaluation measurement (Creswell \& Creswell, 2018; McKenney \& Reeves, 2019). The design and implementation of online orientation programs can be informed by the evaluation of these orientations (McKenney \& Reeves, 2019). Measuring the effectiveness of these supportive interventions can provide an evaluative and reflective base to calibrate existing orientation courses for future versions (Glazer \& Murphy, 2015; McKenney \& Reeves, 2019). Evaluation results from a validated and reliable SOLR instrument can provide more reliable information to enhance the design of effective online learning orientations (OLOs). These are the core concerns at the evaluation and reflection stage of this design research (McKenney \& Reeves, 2019), as illustrated in the conceptual framework Figure 1.

DBR Evaluation-Intended Intervention. The intended intervention of OLO started in the 2014-2015 academic year as the initial stages of analysis and exploration (McKenney \& Reeves, 2019). The problem presented to the researcher was about supporting students enrolled in online courses offered during summer sessions for 4-week, 6-week, and 8-week undergraduate and graduate classes for a residential-oriented comprehensive university focusing on undergraduate education and having master's and doctoral programs. Since students did not have experience participating in fully online classes during regular semesters, technology competencies and online self-directed learning were identified as the core needs through a literature review and preliminary analysis. The analysis also included facility, resource, and context analyses (Diamond, 2011; McKenney \& Reeves, 2019). At the time, the university had just transitioned to a new LMS, Instructure's Canvas. The student support to summer online courses was a companion service to faculty who designed and developed online courses through a campus faculty development program. Therefore the human resources that could be utilized in the design and implementation of the OLO program had to be efficiently budgeted.

The initial exploration stage included site visits and pilot tests of beta orientation design through programs offering online courses during regular semesters. Feedback from faculty members and graduate student focus groups indicated that technology literacy and online learning strategies, such as communication etiquette and time management, were of primary interest.

DBR Evaluation-Implemented Intervention. The design of the online learning orientation was based on the instructional design process model because of its process-oriented focus on analysis, strategies, and evaluation (Smith \& Ragan, 2005). The analysis of the affordances of Canvas LMS unveiled that its customizable learning progress could be used to semiautomate the self-directed learning of students. One outstanding technical feature was the personalized path embedded within the module options. A student would need to complete tasks by the predesigned path. This path was then designed in a sequence of five modules as the intervention, as shown in Figure 2 (Liu \& Adams, 2017).

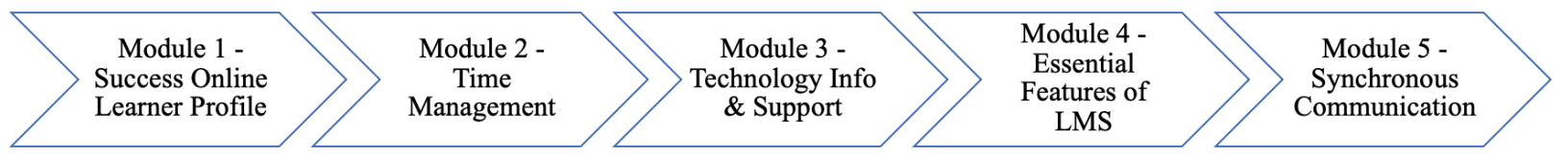

Figure 2. Design and development of online learning orientation. 
The intervention in this study was a self-paced asynchronous orientation course designed, developed, and implemented through the Canvas LMS. The course consisted of five modules: (1) Characteristics of Successful Online Learners, (2) Time Management, (3) Support to Online Learning, (4) Essential Features of LMS, (5) Communication with Synchronous Video Conferencing Technology with End-of-Orientation Feedback (Liu \& Adams, 2017). The prerequisite and requirement functions built in Canvas modules were designed to monitor the asynchronous online progress of users. Each module presented the content with multiple modes in text, images, and videos, and embedded self-directed learning activities for students.

In Module 1, students read a short essay, watched an open-access video about characteristics of successful online learners, and completed a discussion post on their reflection of a successful online student profile. Directions about how to use Canvas discussion were embedded in the module. Students could voluntarily respond to others' posts. In Module 2, students read about time-management strategies and downloaded a template on tracking weekly time distribution on study, work, and other commitments. After completing the template with their own time, students were directed to upload the completed time-management worksheet as an assignment submission. This task was to scaffold the awareness and reflection on effective management of their own time as well as learning the technical procedure of submitting a Canvas assignment and checking a mock grade with feedback. In Module 3, students learned technologysupport information provided by the university. They would also learn how to establish an offcampus virtual private network (VPN) connection by searching a full-text article from the university libraries databases, downloading the article, and uploading it back with a brief reflection on the VPN connection experience. Module 4 was about essential features of the LMS. After reviewing selected tutorials, students were expected to complete a self-assessment quiz as a checking point of task completion. In Module 5, students learned synchronous online participation and communication etiquette by reviewing two infographics, one on being a synchronous presenter and the other on being a synchronous participant. After a voluntary testing session of the synchronous audio and video functions, students were prompted to complete a reflective discussion post. The peer interaction in these modules was all voluntary.

This design project completed two pilot iterations in the 2014-15 and 2015-16 academic years. In the process, the university also switched to a different videoconferencing platform and its integration into Canvas. The formative evaluation utilized student feedback built in the orientation course and a self-reporting questionnaire on user perception that was co-developed by the researcher and a campus assessment center. Along the process, updates of literature review informed the selection of a summative evaluation instrument, the Yu and Richardson SOLR (2015), for the 2017 iteration of the OLO intervention (McKenney \& Reeves, 2019). Because of limited human resources designated for the project, one grader provided feedback in the three iterations between May and August for the 4-week, 6-week, and 8-week summer sessions. The orientation was highly structured and with minimal student-instructor interaction, and focused on selfdirected learning (Liu \& Adams, 2017).

DBR Evaluation-Attended Intervention and Its Effectiveness. As illustrated in Table 2 , the evaluation took a quantitative approach with the pretest $(\mathrm{O} 1)$ and posttest $(\mathrm{O} 2)$ as adapted from the SOLR questionnaire (Yu \& Richardson, 2015; Yu, 2018). The SOLR was selected because it identified the student-instructor and student-student interaction dimensions and was validated. The instrument's validity and reliability tests were performed in the Yu and Richardson study with 331 undergraduate students prior to taking for-credit online courses (2015). In addition 
to the 20 SOLR items, the current study used five demographic questions inquiring about participants' college of study, age group, college year, gender, and student full-time or part-time status.

Table 2

One Group Pretest Posttest Research Method (Creswell, 2014; Creswell \& Creswell, 2018)

\begin{tabular}{ccc}
\hline Pretest & Intervention & Posttest \\
\hline$O 1$ & $X$ & $O 2$ \\
\hline
\end{tabular}

Evaluation context. After the research protocol was approved by the Institutional Review Board (IRB), the researcher conducted the study in a comprehensive university with undergraduates, master's, and doctoral programs on the East Coast of the United States. The anonymous pretest and posttest questionnaires were created and deployed through the university's Qualtrics Web-based survey system. The links were embedded at the beginning and end of the orientation course in the Canvas LMS. The consent form for the pretest questionnaire clearly stated that if consent was not given, the student could still participate in the course and get the support and orientation training.

In mid-April of 2017, a campus email through student Listserv explaining the purpose of the orientation course and then an invitation from the Canvas course were sent to 2,590 students who registered online to take for-credit courses that the university offered for the summer of 2017. These 4-week, 6-week, and 8-week undergraduate and graduate courses lasted for varied amounts of time from early May to mid-August in 2017. With self-selection, students chose whether to participate in the orientation or not. Clear statements were made in both the campus email and the beginning of the orientation course that participation was voluntary and not related to any forcredit coursework performance.

The data collection was concluded in September of 2017. The Canvas analytics indicated that 675 of the students who accepted the Canvas course invitation completed at least one module, and 615 completed all five modules voluntarily. After accepting the course invitation and logging in to the orientation course, 466 students granted their consent and participated in the pretest SOLR survey which was a Web-based survey built with Qualtrics and linked to the beginning of the online orientation. After having completed at least one module or the entire course, 634 students responded to a separate consent form and the posttest SOLR that was linked to the conclusion of Module 5. A separate consent form for pretest and posttest started the survey once a participant clicked the embedded link.

Participants. Among the 466 participants in the pretest (a response rate of 18\%), 445 yielded complete SOLR responses. These participants represented all seven colleges of the university in terms of discipline of study. Among them, 50\% were 18-20 years of age, 39\% were 21-23 years of age, and 11\% were older than 23. Among them, 35\% were seniors, $28 \%$ juniors, $20 \%$ sophomores, $10 \%$ graduate students, and 7\% first-year students. Participants were $76 \%$ female and $24 \%$ male, and there were $86 \%$ full-time and $14 \%$ part-time students. 
Among the 634 participants in the posttest (a response rate of 24\%), 624 yielded complete SOLR responses. These participants also represented all seven colleges of the university. A total of 51\% were $18-20$ years of age, $38 \%$ were $21-23$ years of age, and $10 \%$ were older than 23 , with seven missing responses to the age question. Of the participants, $32 \%$ were seniors, $31 \%$ juniors, 19\% sophomores, $11 \%$ graduate students, and 7\% first-year students. Participants were $76 \%$ female and $24 \%$ male, and there were $86 \%$ full-time and $14 \%$ part-time students among the posttest participants. These demographics only represented the mixed population of traditional on-campus students and nontraditional off-campus students who chose to take summer online courses in the studied institution.

Evaluation data analysis. The primary interest of this study was to find the effectiveness of the self-paced orientation course using the SOLR instrument. To compare the 20 SOLR competencies for those participants who responded prior to taking the orientation course and those responses after taking the course, an independent-samples $t$-test was performed. The second purpose of this study was to find out how the constructs of SOLR correlated with the design and implementation of the self-directed orientation course. Therefore, exploratory factor analyses (EFA) and reliability analyses were executed to evaluate the structure and consistency of the instrument.

\section{Results}

Results of SOLR changes from pretest to posttest. Statistical analysis results of SOLR changes before and after the orientation course. An independent-samples $t$-test was conducted to compare the mean scores of the 20 SOLR items in the pretest and posttest, to initially answer Research Question 1: How has student SOLR changed after taking a self-paced orientation course for online learning? The mean scores of posttest responses to all 20 items were higher than those of pretest (Table 3).

For the construct of technology competency, there was a significant difference in a sense of self confidence in using computer technologies for specific tasks, pretest $(M=4.44, S D=.75)$ and posttest $(M=4.54, S D=0.72) ; t(1,067)=2.13, p=.034$. A significant difference was also found in the perceived proficient in using a wide variety of computer technologies, pretest $(M=$ $4.23, S D=.87)$ and posttest $(M=4.41, S D=.78) ; t(1,067)=3.58, p=.000$. For the tech competency item of feeling comfortable using computers, the difference between pretest and posttest scores was not significant, pretest $(M=4.58, S D=.66)$ and posttest $(M=4.61, S D=.65)$; $t(1,067)=.79, p=.429$. A significant difference was found in in explaining the benefits of using computer technologies in learning, pretest $(M=4.34, S D=.79)$ and posttest $(M=4.52, S D=.69)$; $t(1.067)=3.98, p=.000$. A significant difference was also found in feeling competent at integrating computer technologies into my learning activities, pretest $(M=4.40, S D=.74)$ and posttest $(M=4.55, S D=.67) ; t(1,067)=3.36, p=.001$. There was a significant difference in being motivated to get more involved in learning activities when using computer technologies, pretest $(M=4.19, S D=.87)$ and posttest $(M=4.44, S D=.82) ; t(1,067)=4.81, p=.000$. These results suggest that the self-paced orientation course did significantly change student perceived technology competencies in self-confidence, proficiency, benefits, integration in learning, and motivation in using computer technologies for online learning tasks.

In terms of the construct of social competencies with instructors, there was a significant difference in being able to clearly ask my instructor questions, pretest $(M=4.30, S D=.82)$ and 
posttest $(M=4.61, S D=.65) ; t(1,067)=6.79, p=.000$. A significance difference was found in being able to initiate discussions with the instructor, pretest $(M=4.12, S D=.91)$ and posttest $(M$ $=4.53, S D=.70), t(1,067)=8.28, p=.000$. The competency of seeking help from instructor when needed increased after the posttest with a significant difference, pretest $(M=4.38, S D=.79)$ and posttest $(M=4.62, S D=.64) ; t(1,067)=5.49, p=.000$. A significant difference was also found in timely informing the instructor when unexpected situations arise, pretest $(M=4.38, S D=.80)$ and posttest $(M=4.63, S D=.62), t(1,067)=8.24, p=.000$. There was also a significant difference in the increased competency of expressing my opinions to instructor respectfully, pretest $(M=4.39$, $S D=.79)$ and posttest $(M=4.65, S D=.58), t(1,067)=6.57, p=.000$.

Table 3

Pretest Posttest Mean and Standard Deviation

\begin{tabular}{|llcccc}
\hline \multicolumn{1}{c}{ Factors } & \multicolumn{1}{c}{ Items } & \multicolumn{2}{c}{$\boldsymbol{M}$} & \multicolumn{2}{c}{ SD } \\
\hline Technical & TechComp1 & 4.44 & $4.54^{*}$ & .75 & $.72^{*}$ \\
competencies & TechComp2 & 4.23 & $4.41^{*}$ & .87 & $.78^{*}$ \\
& TechComp3 & 4.58 & $4.61^{*}$ & .66 & $.65^{*}$ \\
& TechComp4 & 4.34 & $4.52^{*}$ & .79 & $.69^{*}$ \\
& TechComp5 & 4.40 & $4.55^{*}$ & .74 & $.67^{*}$ \\
& TechComp6 & 4.19 & $4.44^{*}$ & .87 & $.82^{*}$ \\
\hline Social & SocialComp-Instructor1 & 4.30 & $4.61^{*}$ & .82 & $.65^{*}$ \\
competencies & SocialComp-Instructor2 & 4.12 & $4.53^{*}$ & .91 & $.70^{*}$ \\
with instructor & SocialComp-Instructor3 & 4.38 & $4.62^{*}$ & .79 & $.64^{*}$ \\
& SocialComp-Instructor4 & 4.38 & $4.63^{*}$ & .80 & $.62^{*}$ \\
& SocialComp-Instructor5 & 4.39 & $4.65^{*}$ & .79 & $.58^{*}$ \\
\hline Social & SocialCompPeers1 & 3.15 & $3.81^{*}$ & 1.19 & $1.10^{*}$ \\
competencies & SocialCompPeers2 & 3.41 & $4.09^{*}$ & 1.16 & $1.02^{*}$ \\
with classmates & SocialCompPeers3 & 3.81 & $4.29^{*}$ & .99 & $.86^{*}$ \\
& SocialCompPeers4 & 3.60 & $4.13^{*}$ & 1.11 & $.98^{*}$ \\
& SocialCompPeers5 & 4.18 & $4.52^{*}$ & .98 & $.72^{*}$ \\
\hline Communication & CommComp1 & 4.43 & $4.61^{*}$ & .73 & $.61^{*}$ \\
competencies & CommComp2 & 4.48 & $4.60^{*}$ & .68 & $.62^{*}$ \\
& CommComp3 & 4.48 & $4.62^{*}$ & .66 & $.61^{*}$ \\
& CommComp4 & 4.44 & $4.59^{*}$ & .69 & $.65^{*}$ \\
\hline
\end{tabular}

Note. ${ }^{*}=$ Posttest

For the construct of social competencies with classmates, there was a significant difference in developing friendship with my classmates, pretest $(M=3.15, S D=1.19)$ and posttest $(M=3.81$, $S D=1.10), t(1,067)=9.42, p=.000$. A significant difference was found in paying attention to other students' social actions, pretest $(M=3.41, S D=1.16)$ and posttest $(M=4.09, S D=1.02)$; $t(1,067)=10.14, p=.000$. The increased competency in applying different social interaction skills depending on situations was found having a significant difference, pretest $(M=3.81, S D=.99)$ and posttest $(M=4.29, S D=.86) ; t(1,067)=8.44, p=.000$. A significant difference was also found in the increased competency of initiating social interaction with classmates, pretest $(M=$ $3.60, S D=1.11)$ and posttest $(M=4.13, S D=.98) ; t(1,067)=8.24, p=.000$. There was also a 
significant difference in increased competency of socially interacting with other students with respect, pretest $(M=4.18, S D=.98)$ and posttest $(M=4.52, S D=.72) ; t(1,067)=6.57, p=.000$.

Regarding the construct of communication competencies, there was a significant difference in the increased competency in feeling comfortable expressing my opinion in writing to others, pretest $(M=4.43, S D=.73)$ and posttest $(M=4.61, S D=.61) ; t(1,067)=4.28, p=.000$. A significance difference was also found in feeling comfortable responding to other people's ideas, pretest $(M=4.48, S D=.68)$ and posttest $(M=4.60, S D=.62) ; t(1,067)=3.07, p=.002$. The increased competency in expressing my opinion in writing so that others understand what I mean was also found of significant difference, pretest $(M=4.48, S D=.66)$ and posttest $(M=4.62, S D$ $=.61) ; t(1,067)=3.68, p=.000$. There was also a significant difference in giving constructive and proactive feedback to others even when I disagree, pretest $(M=4.44, S D=.69)$ and posttest $(M=$ $4.59, S D=.65) ; t(1,067)=3.76, p=.000$.

The $t$-test statistical comparison results indicated statistically significant differences in changed SOLR competencies for 19 items, with $p<.05$, after taking the orientation course. The increase for one item was not significant - that is, I feel comfortable using computers.

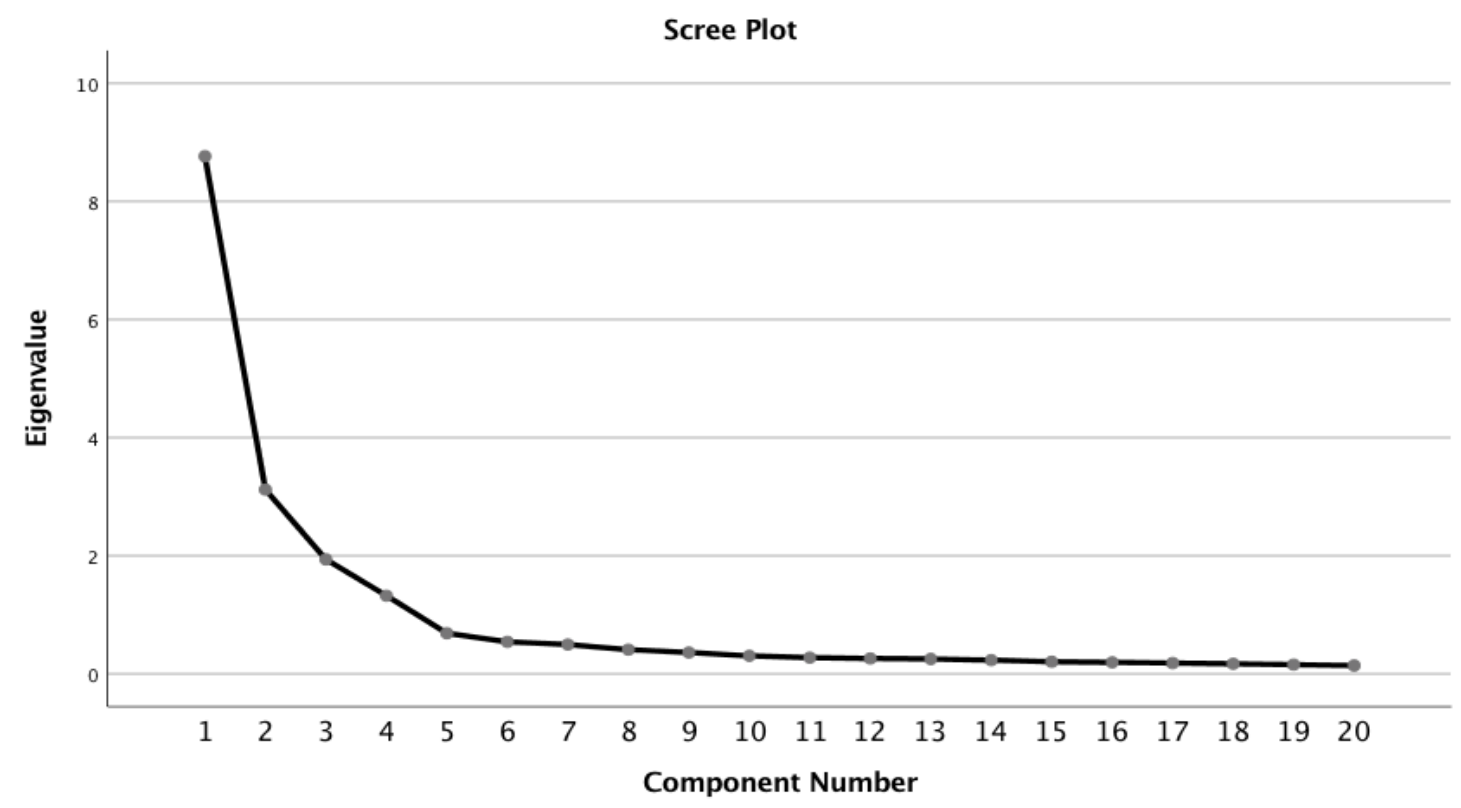

Figure 2. Scree plot of SOLR pretest EFA.

Statistical analysis results with EFA for both pretest and posttest SOLR. The EFA started with an initial analysis of the Kaiser-Meyer-Olkin (KMO) measure of sample adequacy (Meyers, Gamst, \& Guarino, 2006). The KMO of pretest result was .92, indicating that the data were suitable for an EFA analysis. Similarly, Bartlett's test of sphericity was significant, $\chi^{2}(190)=7,238.25(p$ $<.001)$, indicating sufficient correlation between the variables for further analysis. Communalities were fairly high for each of the 20 items, with a range of .55 to .83 . A four-factor structure was clear after a principal component analysis with eigenvalues greater than 1.0, as shown in the scree plot (Figure 2). The four factors accounted for $75.7 \%$ of the total variance. Factor 1 , the six items of technical competencies (eigenvalue $=8.76$ ), accounted for $43.8 \%$ of the variance; Factor 2 , the five-item social competencies with classmates (eigenvalue $=3.12$ ) accounted for $15.6 \%$ of the variance; Factor 3, the five-item social competencies with instructor (eigenvalue $=1.94$ ) accounted 
for $9.69 \%$ of the variance; Factor 4 , the four-item communication competencies (eigenvalue $=1.32$ ) accounted for $6.61 \%$ of the variance.

For the EFA of posttest responses, the KMO was .95. Similarly, Bartlett's test of sphericity was significant, $\chi^{2}(190)=12,394.22(p<.001)$. Communalities were high for each of the 20 items, with a range of .60 to .85 . A three-factor structure was generated after a principal component analysis with eigenvalues greater than 1.0 (Figure 3 ). The three factors accounted for $75.4 \%$ of the total variance. Factor 1, the nine-item combined social competencies with instructor and communication competencies (eigenvalue $=11.46$ ) accounted for $57.3 \%$ of the variance; Factor 2 , the six-item technical competencies (eigenvalue $=2.02$ ) accounted for 10.13 of the variance; Factor 3, the five-item social competencies with classmates (eigenvalue $=1.59$ ) accounted for $7.95 \%$ of the variance.

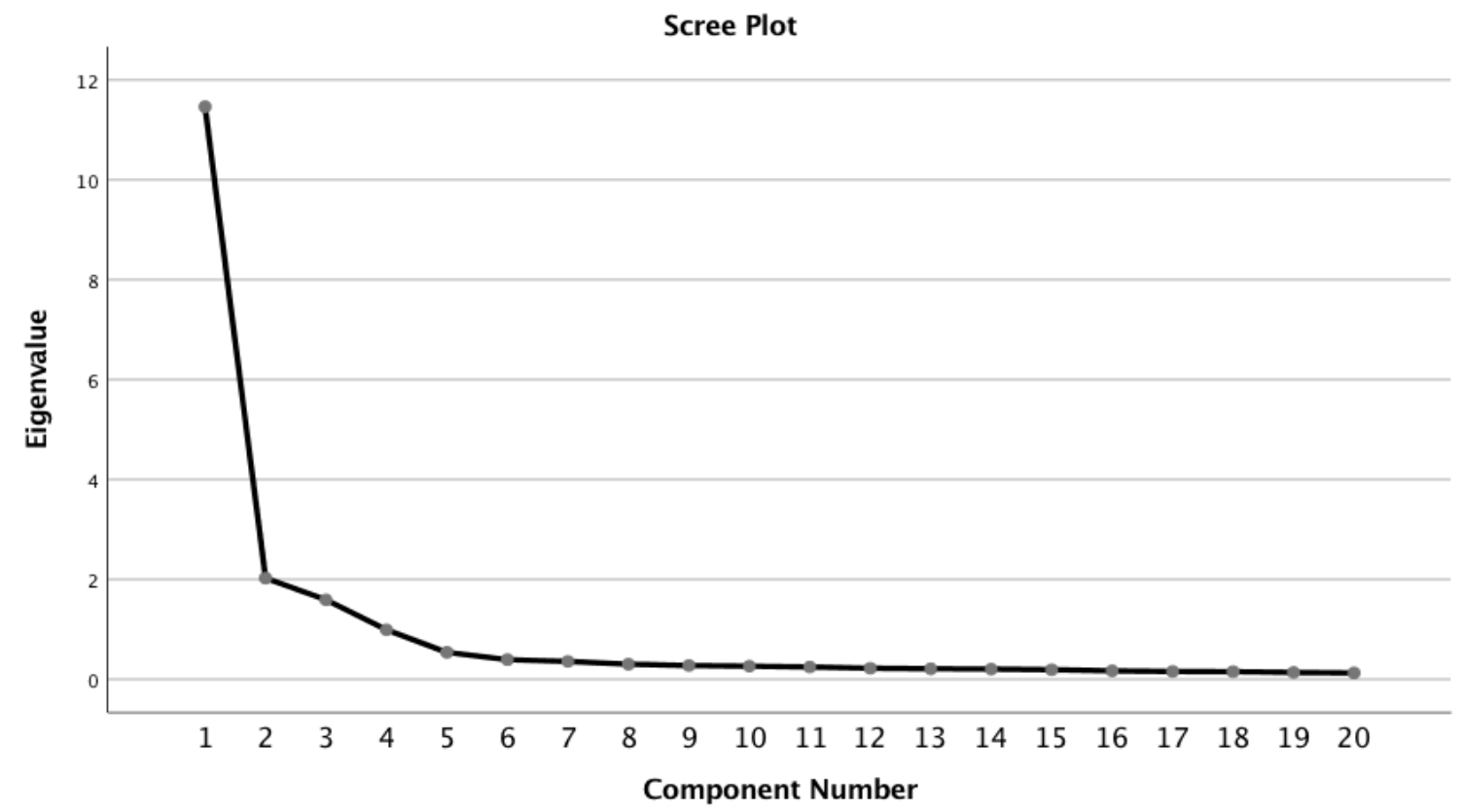

Figure 3. Scree plot of SOLR posttest EFA.

Reliability of the instruments. The Cronbach alphas of the instrument through the pretest $(n=445)$ and discrete constructs were all above .90 , with the 20-item SOLR alpha $=.925$, six-item technical competency alpha $=.922$, five-item social competency with instructor alpha $=.905$, fiveitem social competency with classmates alpha $=915$, and four-item communication competency alpha $=.926$. The Cronbach alphas of the instrument through the posttest $(n=624)$ and discrete constructs were all above .90 as well. Since the structure of the SOLR changed to three constructs, the reliability coefficients indicated as the 20 -item SOLR coefficient $=.955$, six-item technical competency coefficient $=.941$, nine-item social competencies with instructor and communication coefficient $=.951$, and five-item social competency with classmates coefficient $=.914$. 


\section{Conclusion and Discussion}

The key findings of this research were threefold. First of all, this self-paced asynchronous orientation course improved students' online learning readiness in social, technical, and communication domains. Statistically significant improvement was found for 19 out of 20 competencies, except for TechCompetency3: I feel comfortable using computers. The SOLR items provided consistent results and meaningful structure for research inferences as a measurement of online learning readiness (Fraenkel, Wallen, \& Hyun, 2015). The reliability coefficients for each subscale and the SOLR as a whole in the pretest and posttest were high $(\alpha>.90)$. Secondly, student perception of needing peer interaction merged with student-instructor interaction. This indicated the effects of the highly structured nature of this self-directed online orientation course. Students learned the content as guided by the predesigned structure, interacted primarily with the content and one instructor, and perhaps chose not to interact with other peers through online discussion. This was reflected in the changes in the formation of the SOLR constructs. The items loaded to four factors in the pretest, while they reloaded to three factors in the posttest, with nine items of social competencies with instructor and communication competencies loading to one factor. Thirdly, the SOLR instrument (Yu \& Richardson, 2015; Yu, 2018) could be used as an evaluative instrument for the design of online orientation courses.

The response results related to comfort of using computers may be related to the prevalence of using computers to perform learning tasks. In a 2005 study of 4,374 college-age students from 13 institutions, 96.4\% reported using computers for class activities (Kvavik, 2005). The 2017 EDUCAUSE Center for Analysis and Research (ECAR) study reported that $95 \%$ of undergraduate students owned a laptop, and nearly all students had more than one device (Brooks \& Pomerantz, 2017). The combined loading of social competencies with instructor and communication competencies items may be caused by the self-paced nature of the orientation course. Peer interaction in the course communication was not feasible with the volunteering participation. Participants solely interacted with the course and an implicit general instructor, learning LMS and computer literacy and institution support information, performing online communication etiquette with videoconferencing simulation, and completing time-management tasks.

This study has provided evidence of the impact of orientation courses for students taking online courses. It has confirmed the need for online social competency, study strategy, technical, and communication dimensions in the instructional design of online orientations. The study has also provided an evaluation of the use of the SOLR instrument, which is very important when evaluation instruments and methods need validity and reliability evidence (Farid, 2014). Beyond furthering Yu and Richardson's study (2015), the results of this study support the reuse of SOLR for evaluation research, and planning for online student support. The pretest and posttest comparison provides statistical evidence for instructional design enhancement in designing orientation content for online learning.

There are two limitations to this study. One is the sampling being limited to one institution and one pretest and posttest; so the results are not meant to be generalizable. As a major portion of an educational design research, this was just one of multiple subcycles (McKenney \& Reeves, 2019). More cycles with systematic documentation would make the results more generalizable. The second limitation is that the study was deployed by one designer and researcher who also managed the self-paced course. A triangulation of data collection, such as interviews with students, could enhance the study. A closer connection between the orientation with the actual online 
courses would generate more customized results (Carruth et al., 2010; Creswell \& Creswell, 2018; van Rooij \& Zirkle, 2016).

Despite these limitations, this study can offer implications for practice in the design of online learning orientations and related evaluation practices. Because the ubiquitous role of online learning in connecting traditional education with professional and continued education, the social competency developed through peer discourses is critical. With limited resources from academicprogram-offering institutions, open-access communication platforms might be a consideration in the orientation design to connect student peers. In programs that provide the majority of coursework online, group projects can be designed as an integral part of courses and throughout the program. Evaluative practices, informal or formal, can be planned in parallel with such design so that the documentation can be complete and intentional.

Future research related to the design and evaluation of online learning orientation programs presents many opportunities and potential impacts. As more and more online programs are launched to meet the needs of online enrollment, retention improvement, degree completion, and lifelong learning, online learning orientation is becoming the cornerstone of building a successful learning path. Evolving research and design can expand to include online counseling services for adult learners (Robichaud, 2016), to be inclusive with accessibility and universal design considerations (van Rooij \& Zirkle, 2016), to partner with institutional-level policy making and student affairs (van Rooij \& Zirkle, 2016), and to collaborate more closely with instructional personnel who are actually conducting online courses, curriculum, and programs (van Rooij \& Zirkle, 2016). Connecting the design of online learning orientation with students' career-related work is also a future research direction that can meet the needs of working professionals pursuing academic fulfillment (Watts, 2019). 


\section{References}

Baek, E. O., Evans, M. A., \& Barab, S. A. (2013). Activity theory as a lens for characterizing the participatory unit. In D. Jonassen \& M. Driscoll (Eds.), Handbook of research on educational communications and technology (2nd ed., pp. 208-223). New York: Routledge.

Bandura, A. (1989). The multidimensional self-efficacy scales (Unpublished test). Stanford University, Stanford, CA.

Beckford, M. M. (2015). The online learning orientation session: An overlooked retention tool. Distance Learning, 12(4), 43.

Benson, R., \& Samarawickrema, G. (2009). Addressing the context of e-learning: Using transactional distance theory to inform design. Distance Education, 30(1), 5-21.

Brooks, D. C., \& Pomerantz, J. (2017). ECAR study of undergraduate students and information technology.

Carruth, A. K., Broussard, P. C., Waldmeier, V. P., Gauthier, D. M., \& Mixon, G. (2010). Graduate nursing online orientation course: Transitioning for success. Journal of Nursing Education, 49(12), 687-690.

Chan, M. (2017). Have you been oriented? An analysis of new student orientation and eorientation programs at US community colleges. College and University, 92(2), 12.

Cheon, J., Lee, S., Crooks, S. M., \& Song, J. (2012). An investigation of mobile learning readiness in higher education based on the theory of planned behavior. Computers \& Education, 59(3), 1054-1064.

Cho, M. H. (2012). Online student orientation in higher education: A developmental study. Educational Technology Research and Development, 60(6), 1051-1069.

Cho, M. H., \& Heron, M. L. (2015). Self-regulated learning: The role of motivation, emotion, and use of learning strategies in students' learning experiences in a self-paced online mathematics course. Distance Education, 36(1), 80-99.

Cigdem, H., \& Ozturk, M. (2016). Critical components of online learning readiness and their relationships with learner achievement. Turkish Online Journal of Distance Education.

Coleman, A., \& Coleman, M. F. (2013). Activity theory framework: A basis for e-health readiness assessment in health institutions. Journal of Communication, 4(2), 95-100.

Creswell, J. W., \& Creswell, J. D. (2018). Research design: Qualitative, quantitative, and mixed methods approaches. Thousand Oaks, CA: Sage publications.

Dabbagh, N. (2007). The online learner: Characteristics and pedagogical implications. Contemporary Issues in Technology and Teacher Education, 7(3), 217-226.

Diamond, R. M. (2011). Designing and assessing courses and curricula: A practical guide. John Wiley \& Sons.

Dray, B. J., Lowenthal, P. R., Miszkiewicz, M. J., Ruiz-Primo, M. A., \& Marczynski, K. (2011). Developing an instrument to assess student readiness for online learning: A validation study. Distance Education, 32(1), 29-47. 
Entwistle, N., \& Ramsden, P. (2015). Understanding student learning. Routledge.

Farid, A. (2014). Student online readiness assessment tools: A systematic review approach. Electronic Journal of e-Learning, 12(4), 375-382.

Fraenkel, J. R., Wallen, N. E., \& Hyun, H. H. (2015). How to design and evaluate research in education (9th ed.). New York: McGraw-Hill.

Gilmore, M., \& Lyons, E. M. (2012). Nursing 911: An orientation program to improve retention of online RN-BSN students. Nursing Education Perspectives, 33(1), 45-47.

Glazer, H. R., \& Murphy, J. A. (2015). Optimizing success: A model for persistence in online education. American Journal of Distance Education, 29(2), 135-144.

Gray, B. (2004). Informal learning in an online community of practice. Journal of Distance Education, 19(1), 20-35.

Horzum, M. B., Kaymak, Z. D., \& Gungoren, O. C. (2015). Structural equation modeling towards online learning readiness, academic motivations, and perceived learning. Educational Sciences: Theory and Practice, 15(3), 759-770.

Hung, M. L., Chou, C., Chen, C. H., \& Own, Z. Y. (2010). Learner readiness for online learning: Scale development and student perceptions. Computers \& Education, 55(3), 1080-1090.

Johnson, R., Stewart, C., \& Bachman, C. (2015). What drives students to complete online courses? What drives faculty to teach online? Validating a measure of motivation orientation in university students and faculty. Interactive Learning Environments, 23(4), $528-543$.

Kaptelinin, V., \& Nardi, B. A. (2006). Acting with technology: Activity theory and interaction design. MIT press.

Kauffman, H. (2015). A review of predictive factors of student success in and satisfaction with online learning. Research in Learning Technology, 23. https://doi.org/10.3402/rlt.v23.26507

Kaymak, D. Z., \& Horzum, M. B. (2013). Relationship between online learning readiness and structure and interaction of online learning students. Educational Sciences: Theory and Practice, 13(3), 1792-1797.

Kim, J., Kwon, Y., \& Cho, D. (2011). Investigating factors that influence social presence and learning outcomes in distance higher education. Computers \& Education, 57(2), 15121520.

Kvavik, R. B. (2005). Convenience, communications, and control: How students use technology. Educating the Net Generation, 1(2005), 7-1.

Lee, S. M. (2014). The relationships between higher order thinking skills, cognitive density, and social presence in online learning. The Internet and Higher Education, 21, 41-52.

Lieberman, M. (2017, September 13). Orientation programs set online learners success. Inside Higher Ed. Retrieved from https://www.insidehighered.com/digitallearning/article/2017/09/13/orientation-programs-set-online-learners-success 
Liu, J. C., \& Adams, A. (2017). Design of online student orientation with conceptual and procedural scaffolding. In F. Q. Lai \& J. D. Lehman (Eds.), Learning and knowledge analytics in open education (pp. 41-68). New York, NY: Springer.

Liu, J. C., \& Roberts-Kaye, E. (2016). Preparing online learning readiness with learner-content interaction: Design for scaffolding self-regulated learning. In L. Kyei-Blankson, J. Blankson, E. Ntuli, and C. Agyeman (Eds.), Handbook of research on strategic management of interaction, presence and participation in online courses (pp. 216-243). Hershey, PA: IGI Global.

McKenney, S., \& Reeves, T. C. (2019). Conducting educational design research. Routledge.

Moore, M. G., \& Kearsley, G. (2011). Distance education: A systems view of online learning. Cengage Learning.

Mosa, A. A., Mahrin, M. N. bin, \& Ibrrahim, R. (2016). Technological aspects of e-learning readiness in higher education: A review of the literature. Computer and Information Science, 9(1), 113-127.

Online Learning Consortium. (2016). Quality scorecard for the administration of online programs.

Pintrich, P. R., Garcia, T., McKeachie, W. J., \& Smith, D. A. (1991). Motivated strategies for learning questionnaire. Regents of the University of Michigan.

Robichaud, W. (2016). Orientation programs to increase retention in online community college courses. Distance Learning, 13(2), 57-64.

Scagnoli, N. I. (2001). Student orientations for online programs. Journal of Research on Technology in Education, 34(1), 19-27.

Scanlon, E., \& Issroff, K. (2005). Activity theory and higher education: Evaluating learning technologies. Journal of Computer Assisted Learning, 21(6), 430-439.

Seaman, J. E., Allen, I. E., \& Seaman, J. (2018). Grade increase: Tracking distance education in the United States. Babson Survey Research Group.

Smith, P. J., Murphy, K. L., \& Mahoney, S. E. (2003). Towards identifying factors underlying readiness for online learning: An exploratory study. Distance Education, 24(1), 57-67.

Smith, P. L., \& Ragan, T. J. (2005). Instructional design. John Wiley \& Sons.

So, H. J., \& Brush, T. A. (2008). Student perceptions of collaborative learning, social presence and satisfaction in a blended learning environment: Relationships and critical factors. Computers \& Education, 51(1), 318-336.

Swan, K. (2001). Virtual interaction: Design factors affecting student satisfaction and perceived learning in asynchronous online courses. Distance Education, 22(2), 306-331.

Swan, K. (2002). Building learning communities in online courses: The importance of interaction. Education, Communication \& Information, 2(1), 23-49.

Taylor, J. M., Dunn, M., \& Winn, S. K. (2015). Innovative orientation leads to improved success in online courses. Online Learning, 19(4), n4. 
Tinto, V. (1975). Dropout from higher education: A theoretical synthesis of recent research. Review of Educational Research, 45(1), 89-125.

Tomei, L., Hagel, H., Rineer, A., Mastandrea, L. A., \& Scolon, J. (2009). Do orientation materials help students successfully complete online courses? International Journal of Information and Communication Technology Education (IJICTE), 5(2), 73-89.

Uden, L. (2006). Activity theory for designing mobile learning. International Journal of Mobile Learning and Organization, 1(1), 81-102.

van Rooij, S. W., \& Zirkle, K. (2016). Balancing pedagogy, student readiness and accessibility: A case study in collaborative online course development. The Internet and Higher Education, 28, 1-7.

Watts, J. (2019). Assessing an online student orientation: Impacts on retention, satisfaction, and student learning. Technical Communication Quarterly, 1-17.

Williams, P. E., \& Hellman, C. M. (2004). Differences in self-regulation for online learning between first-and second-generation college students. Research in Higher Education, 45(1), 71-82.

Yilmaz, R. (2017). Exploring the role of e-learning readiness on student satisfaction and motivation in flipped classroom. Computers in Human Behavior, 70, 251-260.

Yu, T. (2018). Examining construct validity of the Student Online Learning Readiness (SOLR) instrument using confirmatory factor analysis. Online Learning, 22(4), 277-288.

Yu, T., \& Richardson, J. C. (2015). An exploratory factor analysis and reliability analysis of the Student Online Learning Readiness (SOLR) instrument. Online Learning, 19(5), 120141.

Yukselturk, E., \& Bulut, S. (2007). Predictors for student success in an online course. Journal of Educational Technology \& Society, 10(2), 71-83. 